\title{
iVamos al Centro Comercial! Consumo y visualidades del miedo en la Medellín contemporánea*
}

\author{
Carlos Mario Berrío Meneses* \\ Recibido: 2014 09-10 - Aprobado por pares: 2014-11-30 \\ Enviado a pares: 2014-10-10 - Aceptado: 2014-12-03
}

\section{Resumen}

El presente artículo explora cómo la combinación de dos factores: el miedo y la sociedad de consumo se han convertido en uno de los motores fundamentales del crecimiento de los centros comerciales urbanos en Colombia y especialmente en la ciudad de Medellín. Allí, se fomenta el consumo de productos y servicios y, al mismo tiempo, se invita a los consumidores a escapar de los peligros inherentes de vivir en la ciudad contemporánea.

Palabras clave: Centros comerciales, Medellín, Miedo, Consumo, Publicidad.

* $\quad$ El presente artículo nace como un resultado de la investigación titulada Visualidades del miedo; heroísmos y villanías en la Medellín contemporánea, desarrollada en la Facultad de Comunicación de la Universidad de Medellín y financiada por la Vicerrectoría de Investigaciones de la Universidad de Medellín.

** Publicista y Magíster en Estudios Políticos. Actualmente docente investigador de la Universidad de Medellín. Coordinador de la Maestría en Comunicación de la misma universidad. Correo electrónico: caberrio@ udem.edu.co 


\title{
Let's Go to the Mall! Consumption and Visualization of Fear in Contemporaneous Medellín
}

\begin{abstract}
This article explores how the combination of two factors: fear and consumer's society have become one of the key growth drivers of shopping mall in Colombia and especially in Medellin. In these places, the consumption of products and services is encouraged and at the same time, consumers are invited to escape from the inherent dangers of living in a contemporary city.

Key words: Shopping mall, Medellin, Fear, Consumption, Advertising.
\end{abstract}




\section{Introducción}

Los centros comerciales en Colombia, y especialmente en la ciudad de Medellín, han demostrado un crecimiento considerable durante los últimos años. Según Fenalco, el negocio mueve cerca de $\$ 26$ billones anuales en Colombia y las inversiones proyectadas entre 2013 y 2015 superan los US\$2000 millones, puesto que se contempla la creación de 50 proyectos en todo el país (revista P\&M, 2013). Por otra parte, de acuerdo con la Asociación de Centros Comerciales de Colombia, Medellín se ubica en un lugar destacado en cuanto al área construida de este tipo de establecimientos. Si se revisa el contexto latinoamericano, el promedio regional se ubica en $8.22 \mathrm{~m} 2$ construidos por cada 100 habitantes, mientras Medellín tiene un promedio de $17.20 \mathrm{~m} 2$, por encima de Cali y Bogotá, respectivamente. Además, entre 2013 y 2014 se espera un aumento superior a los 208.168 metros cuadrados de espacio comercial en el área metropolitana (El Colombiano, 2013).

Desde esta perspectiva, no resulta extraño que la clase media medellinense haya aceptado los centros comerciales no solo como un espacio donde se compra, sino también como un lugar donde se conjugan el ocio, el entretenimiento y la vida social. Así, para muchos medellinenses, el plan de fin de semana obligatoriamente incluye visitar estos establecimientos e invertir allí una considerable cantidad de tiempo. Por tal razón, cerca del $47 \%$ de quienes asisten a estos espacios comerciales permanecen en sus instalaciones entre dos y cuatro horas cada vez que los visitan.

Entre los argumentos que este sector expone para explicar el rápido crecimiento de los centros comerciales en Colombia -y en la ciudad de Medellín-, sobresale la abundante inversión extranjera que ha llegado al país en los últimos años, la cual se ha combinado con tres factores concretos. Primero, el diseño: este tipo de establecimientos comerciales ha invertido grandes esfuerzos en hacer sus espacios más amables, interesantes e innovadores, situación que facilita la vivencia de experiencias para los consumidores. Segundo, precio competitivo: la amplia oferta comercial surgida en Colombia ha permitido que las marcas ubicadas en centros comerciales ofrezcan sus productos a precios competitivos. El antiguo imaginario que existía en torno a que las compras en estos establecimientos eran por lo general más costosas ha desaparecido. Tercero, estrategias de mercadeo definidas: Inicialmente los centros comerciales se limitaban a unas acciones en específicas épocas del año; hoy día, estos establecimientos han desarrollado estrategias de marca mucho más agresivas. Por esta razón, han construido una relación más cercana con sus consumidores, los cuales perciben estos negocios como un espacio para el encuentro.

Sin embargo, los factores anteriormente descritos, por sí solos, son insuficientes para explicar este fenómeno puesto que, aunque cualquier centro comercial deberá realizar acciones de este tipo para mantenerse como una opción rentable en el mercado, estos no explican el crecimiento acelerado de todo el sector. Para entenderlo, deberemos sumarle dos factores que no han sido tenidos en cuenta hasta el momento: la sociedad de consumo y los miedos contemporáneos. 
Jean Baudrillard expuso en 2009 uno de los primeros esbozos para entender la sociedad de consumo. Esta fue catalogada por el autor, como la economía del signo. Es decir, asistimos a un modelo económico que no intercambia simplemente mercancías, sino algo más importante o significativo: símbolos. Los consumidores hoy día no compramos objetos para satisfacer nuestras necesidades, sino que compramos objetos por lo que estos representan para nosotros. Nos convertimos en una sociedad fetichista, pues giramos en torno a la producción, el consumo y la exhibición de los objetos (Álvarez y Arango, 2011).

Asimismo, el autor afirma que el consumo se ha presentado como la respuesta a una gran interrogante que nos aqueja desde el origen de la civilización: ¿cómo ser felices? La respuesta es simple, el consumo nos hará felices y entre más se consuma más felices seremos. Entonces el centro comercial no solo nos ofrece la posibilidad de consumir y entretenernos, sino la oportunidad de ser felices.

Hasta aquí el primer elemento que explica el éxito de este negocio: la sociedad de consumo. Ahora, el segundo elemento está basado en el miedo que sentimos dentro de la ciudad y hacia ella -escenario propio de la Contemporaneidad-. El miedo es definido de diversas formas, pero esencialmente puede entenderse como una emoción natural desarrollada como mecanismo de supervivencia que se desata ante una amenaza o un peligro.

Adicional a esto, Enrique Gil Calvo (2004) afirma que la sociedad contemporánea e hipercomunicada entiende el mundo como un sitio tremendamente peligroso. Convivimos con la permanente sensación de riesgo e incertidumbre, fundamentados en que las nuevas tecnologías de la información y la comunicación están al alcance de millones de personas, que pueden enterarse rápidamente de peligros que ocurren a miles de kilómetros de distancia. A manera de ejemplo: las posibilidades de tener una muerte violenta en la Edad Media eran mucho más altas que hoy día; inclusive, llegar a la vejez podría considerarse un asunto relativamente extraño. Sin embargo, a diferencia de quienes vivieron en ese período, hoy día vivimos aterrados de la posibilidad de ser víctimas debido a que hechos peligrosos llegan a las pantallas de nuestros televisores, laptops y smartphone a diario; todo esto, aun cuando la expectativa de vida ha aumentado considerablemente en las últimas décadas y las probabilidades de ser víctimas de un acto de violencia extrema han disminuido.

Como perceptores de los mensajes de comunicación, somos inundados por mensajes que reproducen el miedo: los noticieros en diversos formatos presentan a diario extorsiones, asesinatos, robos, accidentes fatales, calamidades, etc. A esto se suman numerosos programas de televisión que tienen como tema principal la inseguridad y la victimización, los cuales se combinan con cadenas de correos electrónicos que circulan mientras denuncian las nuevas modalidades de robos en la ciudad; adicionalmente, la violencia experimentada en la ciudad de Medellín en las últimas décadas, por medio de la transformación y el aumento de múltiples factores de riesgo, lo cual produce una sensación de temor hacia los sitios públicos, y en algunos casos, también hacia los sitios donde se habita. 
Impulsados en una postura reflexiva, este trabajo pretende reconocer cómo los centros comerciales y otro tipo de recursos que limitan la vivencia del espacio público se han convertido en instrumentos que aumentan la sensación de seguridad. Para ello, se explorarán los conceptos de la sociedad del consumo y los miedos contemporáneos; luego se profundizará en los miedos que aquejan a la ciudad de Medellín y finalmente se abordará el tema de cómo los centros comerciales se han convertido en una opción viable para huir del miedo y hoy día pretenden ser el lugar donde se combinan la seguridad y la felicidad.

\section{Metodología}

Esta investigación exploratoria partió del supuesto de que los medios de comunicación construyen percepciones en el público con respecto al miedo, razón por la cual, estos influyen en cómo se advierten los peligros, las amenazas y el miedo por parte de la opinión pública. En este sentido, las fuentes del miedo hechas visibles en los medios masivos no responden únicamente a un interés de los equipos periodísticos por retratar el entorno o de los expertos en mercadeo y publicidad para promover cierto tipo de bienes y servicios, sino que también ayudan a formar dicha realidad en la medida en que se convierten en una nueva fuente de miedo en sí misma. Así, los temores retratados en los medios de comunicación se hacen cada vez más visibles e impulsan a la opinión pública a responder ante las amenazas allí presentadas.

Por tal razón, el equipo de investigación se centró en la metodología de análisis de contenido en el medio de información escrito de mayor circulación en la ciudad; se tomó como muestra principal al periódico El Colombiano y la indagación se centró en el transcurso de los años 2008-2011. Con el fin de delimitar la muestra, se escogió al azar una publicación mensual, alternando las semanas y los días, procedimiento que permitió limitarla a 48 ejemplares de todos los días de la semana.

Dicho rastreo permitió una revisión exploratoria de los tipos de noticias que conformaban las primeras páginas y el primer cuadernillo; esta observación se realizó para de determinar qué tipos de amenazas se encontraban manifiestas en las primicias del periódico y qué información representaba (de alguna manera) peligro para los lectores; esto con la intención de comprobar si los supuestos del equipo investigador acerca del tema eran congruentes con los resultados obtenidos.

La hipótesis sobre el que se realizó la investigación plantea que el miedo es un resultado de la violencia física a la que ha estado condicionada la ciudad desde finales de los años ochenta; sin embargo, el material escrutado permitió hallar cuatro tipos diferentes de miedo que se podrían clasificar de la siguiente manera: Primero: miedo por la seguridad física, materializado en violencia en las calles, homicidios, paros armados, extorsiones, etc. Segundo: miedo asociado a factores económicos, centrados principalmente en la disminución en la calidad de vida, carencia o pérdida del empleo. Tercero: miedo a los cambios climáticos que afectan a la población por medio de derrumbes derivados del invierno (aludes), inundaciones, sequías, incendios. Cuarto: miedo a las enfermedades, 
principalmente a las que son catalogadas como ruinosas, que estén por fuera del Plan Obligatorio de Salud y enfermedades infectocontagiosas.

Posterior a la clasificación de dichos conceptos, se procedió a caracterizar los hechos noticiosos que trataban temas relacionados y que hacían parte de la primera página de cada ejemplar; en estas noticias se empleó la metodología de análisis de contenido. Adicionalmente, el equipo de investigación realizó un rastreo paralelo en dos ámbitos enteramente diferentes; en primer lugar, en torno a cómo se visualizan estos miedos -y otros no evidenciados en las noticias- en la publicidad pautada en este medio de comunicación, y en segundo lugar, se rastreó la ficción narrativa de la ciudad, producida en cortos y largometrajes producidos en la ciudad en el mismo período. Si bien, el equipo desde un principio tenía claro que la ficción no tiene una obligación documental o periodística de narrar la realidad, sí proyecta interpretaciones de lo real y retrata de alguna manera los imaginarios de la ciudad.

Finalmente, después de estudiar los tres campos, noticioso, publicitario y audiovisual, se contrastaron los hallazgos por medio de una encuesta de opinión realizada por el Centro de Opinión Pública de la Universidad de Medellín, con la cual se pretendía determinar si los miedos visualizados en estos campos, efectivamente estaban apropiados por diferentes sectores de la opinión pública de la ciudad de Medellín.

\section{La sociedad de consumo}

Diversos académicos contemporáneos han coincidido en calificar a la Modernidad como un concepto netamente occidental. Es decir, las ideas de este período, que aparentemente son universales, en realidad surgen paulatinamente al finalizar la Edad Media en Europa y posteriormente se expanden a diferentes regiones del mundo, apoyadas en el poderío militar y naval que los europeos experimentaron desde mediados del siglo XVII. Desde esa perspectiva, puede entenderse por qué el continente americano adoptó, de una manera más o menos homogénea, los valores de la Modernidad.

Según Carlos Patiño (2006), estos valores pueden categorizarse claramente en unos pocos elementos que identifican inequívocamente a una sociedad moderna. Estos valores han permitido el triunfo de un determinismo económico que nos lleva a pensar que una sociedad se moviliza, básicamente, por estos intereses y que estos pueden ser gestionados políticamente. Así, el crecimiento económico se convierte en un elemento fundamental para medir el desarrollo y bienestar de una sociedad. Desde esta perspectiva, no resulta extraño que el consumo haya surgido como un elemento primordial que identifica a las sociedades modernas y más adelante a las posmodernas. En este campo se han destacado los trabajos de los sociólogos Jean Baudrillard (2009) y Zygmunt Bauman (2007) quienes han realizado esbozos teóricos que buscan explicar cómo funcionan las sociedades basadas en el consumo.

Como se dijo anteriormente, Baudrillard expone que la sociedad de consumo es en realidad una sociedad fetichista que gira en torno a la producción, compra y exhibición 
de los objetos. Así, los objetos ya no se limitan a cumplir una función de uso, sino que van mucho más allá y pasan a expresar significados más profundos como la distinción, y la exclusividad o, incluso, dan a conocer los intereses, gustos y estilos de vida de quienes los usan y exhiben. En esta lógica, los objetos buscan transmitir cualidades que también pueden extenderse a los usuarios, pues ellos también se comportan, de alguna manera u otra, como un producto digno de ser consumido. Bauman (2007, 17 y ss.) es claro en afirmar que los consumidores son promotores del producto que usan y, al mismo tiempo, son un producto que promueven constantemente. Los consumidores se convierten en gerente de ventas, vendedor ambulante y producto al mismo tiempo. No resulta en vano nuestra obsesión por los salones de belleza, los gimnasios, los tintes de cabello, los trucos para verse joven, eliminar las arrugas, etc., que buscan ofrecerles a los cuarentones la oportunidad de sentirse y sobre todo verse jóvenes para no ser descartados por anticuados u obsoletos; para ser comprados y usados por otros.

La sociedad de consumo, llamada por Bauman "sociedad de consumidores", lentamente se ha encargado de refundar las interacciones humanas a imagen y semejanza de las relaciones que se establecen entre consumidores y productos. Es decir, en una relación entre consumidores y productos, se presume que los consumidores humanos pueden elegir entre muchos tipos de productos, probarlos, descartarlos, ignorarlos, usarlos y finalmente desecharlos. Así, el consumidor humano puede elegir y los productos pueden ser elegidos o descartados. Sin embargo, lo que en realidad sucede en este tipo de sociedad es que los roles son borrosos y terminan por confundirse. En la sociedad de consumidores, nadie puede convertirse en un sujeto si no está dispuesto a convertirse al mismo tiempo en un objeto, en un producto, y al mismo tiempo, someterse a todas las posibilidades que esto encarna, es decir, a ser elegido o ignorado, a ser usado y finalmente desechado.

Desde esta perspectiva no resulta extraño el afán de millones de personas por adquirir la fama y el reconocimiento. Esta no es otra cosa que el deseo de destacarse y salir del anonimato, adquirir la capacidad de aparecer en portadas de revistas, pantallas de televisor y convertirse en tema de conversación porque así presuntamente se adquiere la capacidad de ser deseado, amado y consumido, como lo son también los objetos exhibidos en las vitrinas. El famoso adquiere la misma capacidad y el mismo comportamiento de los zapatos de última moda o aquellos accesorios que titilan en la pantalla del televisor.

Bajo esta misma perspectiva, puede también entenderse el impresionante éxito de diversas redes sociales, que buscan exhibir a las personas como se hace con un objeto de consumo. Así, la creación de un perfil de usuario y la posibilidad de intercambiar fotografías y de exponer en público lo que tradicionalmente se conoce como la vida privada en realidad obedece a ese interés y necesidad de exhibirse como producto y conseguir más amigos virtuales, fans o seguidores que comprueben esa posibilidad de ser deseado. Se busca, de igual forma, la posibilidad de ser famoso, de aparecer en una vitrina para salir del anonimato y destacarse de la misma forma en que lo hace un producto exitoso. 
Una dinámica relativamente parecida opera en las agencias de citas que proliferan en Internet y que día a día le ganan terreno a estas agencias que funcionan en el plano físico. Sus usuarios buscan encontrar a la pareja ideal como quien busca un producto de consumo. Buscan a través de unas categorías que clasifican a las personas a través de color del cabello, ojos, estatura, peso, hobbies, actividades y nivel de estudios (entre otras opciones) y esperan encontrar a través de unos cuantos clics a esa persona especial que los hará felices. Sin embargo, quienes son los usuarios más avanzados en este tipo de servicios ofrecidos en la red son quienes más incomodidades tienen para socializar con una persona real, "de carne y hueso", puesto que han sido malcriados por el facilismo de la sociedad de consumo. La escogencia de una pareja sentimental y la construcción de una relación duradera, exigen un nivel relativamente alto de tolerancia y paciencia. Entender al otro, no juzgarlo, apoyarlo constantemente y crecer juntos son actividades que no siempre resultan una tarea fácil; todo lo contrario, exigen un alto nivel de reflexión interior, el cual no se da dentro de las dinámicas del consumo (Bauman 2007).

Los consumidores enfrentados a inconvenientes o insatisfacciones con sus productos no se someten a autocríticas, ni apelan a su tolerancia y paciencia. Simplemente recurren a una fórmula bien desarrollada por el consumismo: cambian de producto, lo renuevan por uno mejorado. Los consumidores avanzados y privilegiados lo hacen automáticamente, y sin pensarlo, desechan ese producto que se considera obsoleto o de mala calidad. No resulta extraño que el concepto de la obsolescencia programada, donde los objetos tienen una vida útil relativamente corta, haya permeado otros ámbitos de la vida diaria. Así, las relaciones de pareja, las relaciones afectivas, los vínculos laborales, etc., tienen una vida efímera. Bauman ha sabido entender esto a través de su metáfora de lo líquido como una clave para entender el mundo de hoy. Así ha descrito como líquidos los miedos, la Modernidad, el amor, etc., para describir el estado de lo transitorio y el rechazo a lo duradero (Álvarez y Arango, 2011).

Aquí cobra especial importancia la publicidad como aquella herramienta comercial encargada de exacerbar el deseo del consumidor y, por tanto, mantener un interés constante en los nuevos productos que está ofreciendo el mercado. De igual forma, se convierte en la herramienta que ofrece la felicidad como recompensa al consumo de nuevos productos, una felicidad que nunca se hace realidad, puesto que siempre hay un nuevo producto por comprar y consumir. La marca como concepto privilegiado de la publicidad aparece para obviar el valor de uso del producto y fortalecer la relación emocional y psicológica que se crea entre dicho producto y el consumidor, a través de la promesa de valores de carácter emocional como el prestigio, la exclusividad, la tranquilidad, la satisfacción, la posibilidad de ser amado o deseado, ser exitoso, divertido, interesante y notorio, entre otros. El concepto de la marca ayuda a entender por qué en la sociedad de consumidores no solo se consumen los productos, sino que se crean cultos en torno a los valores de la marca (Atkin, 2004).

En un mundo donde los valores de la Modernidad enfrentan un declive o, por lo menos una crisis, explicada por Lyotard (1991) como la crisis de los meta-relatos, la marca y sus promesas aparecen en la sociedad de consumidores, como esa nueva institución que 
reemplaza a las instituciones tradicionales y a las ideologías que las soportan. Millones de personas encuentran en las marcas esa pertenencia a un grupo y al mismo tiempo, la posibilidad de destacarse entre sus pares (Atkin, 2004). El consumidor asume que si la marca y su discurso son exitosos y amados, al ser seguidos y apropiados por él, conseguirá obtener el mismo éxito y posibilidad de ser deseado.

\section{El miedo y sus visualidades}

El miedo puede definirse desde diversos campos y perspectivas; puede entenderse como una emoción, pero al mismo tiempo como un recurso político. Esta notable diferencia se entiende gracias a que el miedo se ha convertido en objeto de estudio desde hace un buen tiempo. Es Delumeau (1989) quien podría considerarse el más importante autor que lo define como una emoción, pues lo aborda desde una perspectiva clínica y afirma que el miedo es entendido como una emoción de choque, frecuentemente precedida por la sorpresa, provocada por la toma de conciencia de un peligro presente y agobiante que, según creemos, amenaza nuestra conservación. Asimismo, afirma este autor que el miedo es un asunto natural, debido a que todas las especies animales sienten miedo como un mecanismo de supervivencia. Sin embargo, ninguna especie siente tanto miedo como el hombre, puesto que su imaginación le permite prever su inevitable muerte, razón por la cual su miedo, producto de su imaginación, es tan constante y duradero.

Es necesario decir que Delumeau también aclara que si bien el miedo se origina como respuesta a una amenaza que por lo general pone en peligro nuestra vida, también se puede extender a otro tipo de eventualidades que no comprometen la supervivencia sino los privilegios, las comodidades y esencialmente la sensación de seguridad.

La posición de Delumeau es acompañada por Camiñas (2007), Carman (2008) y Marina (2009), quienes, con algunas diferencias, ubican al miedo como un asunto emocional que surge como respuesta a una amenaza real o imaginaria. Es decir, el miedo no es una emoción en sí, sino que surge como respuesta a algo bien definido. Así las cosas, el miedo se diferencia de la angustia porque en esta última, la amenaza no es concreta y quienes son víctima de esta no pueden enfrentarlo adecuadamente pues no saben a qué le temen, simplemente temen.

Por otra parte, el miedo también puede ser definido como un sentimiento. Es decir, además de ser considerado una emoción, está determinado por las diversas condiciones históricas particulares que sugieren temor. Así, los miedos particulares experimentados por un pueblo en una determinada época pueden ser muy diferentes a los de otro colectivo, debido a que lo que aprendemos a sentir está notablemente influenciado por el contexto social. En este sentido, para ser muy puntuales, los mitos y leyendas típicas del departamento de Antioquia en Colombia, se remiten a un contexto rural de montañas y bosques exuberantes, donde personajes como las brujas, la Llorona o la Madremonte tienen facetas dignas de ser temidas en ese contexto específico, cosas que hoy día -en el contexto urbano- no asustan a nadie, en la medida en que no hemos aprendido a temer a estos personajes. 
En este punto, también se destaca Delumeau como el principal historiador del miedo, quien en su obra El miedo en Occidente: siglo XVI-XVIII (1989), hace un recorrido histórico de los elementos o situaciones a los cuales los pueblos occidentales tradicionalmente han temido. Por tal razón, afirma que los pueblos desarrollan el hábito de temer más a unas cosas que a otras. A este autor se le suma Enrique González Duro (2007) quien realiza un estudio histórico del miedo desde la Edad Media hasta la Posmodernidad. González afirma que el miedo es un sentimiento que se origina en lo individual o en lo colectivo, pero que esencialmente, puede contagiarse y de esta manera ser usado para controlar a una amplia población. Así, este sentimiento ha resultado ser una poderosa herramienta para ejercer el control social por parte de poderes hegemónicos - a quienes el autor llama "los fabricantes del miedo" - que lo han utilizado (y hoy día lo utilizan) para doblegar a la sociedad.

Esta posición es compartida por Corey Robin (2004), quien claramente califica a Tomas Hobbes como uno de los principales teóricos del miedo político, quien sostenía que esta era una poderosa herramienta al servicio de los Estados con el fin de mantener el control sobre la población que se gobernaba. Desde esta perspectiva, el Estado debía, por una parte, desarrollar castigos ejemplarizantes contra los que se levantaban en su contra, y por otra, debía promulgar el temor a la muerte. Es decir, valores como el honor, el deber y la valentía debían ser menospreciados por el Estado y la sociedad misma, ya que estos valores son importantes métodos que se utilizan para superar los temores que se tienen hacia la muerte. Así, eliminadas estas herramientas -entre las que se incluye el heroísmo-, la sociedad temería a la muerte y, por tanto, se vería a obligada a obedecer al Estado, quien sería la única institución autorizada para causar la muerte de una persona.

Puede establecerse una importante relación entre el trabajo de Hobbes y el de otros autores como Foucault con su obra Vigilar y castigar. Nacimiento de la prisión (1980) y George Balandier (1994) y su obra El poder en escenas, puesto que Hobbes plantea que el miedo no puede surgir al azar, sino que debe ser creado por el Estado y expandido por toda la sociedad a través de una serie de instituciones como la prisión, la iglesia o la universidad que deben utilizar la teatralidad para expandir este sentimiento en la totalidad de la sociedad y así asegurar la efectividad del mensaje.

Por otra parte, el miedo también tiene una relación profunda con el aspecto comunicacional debido a que esta emoción tiene una existencia real en el lenguaje. Por tal razón, no son pocos los autores que han buscado establecer las relaciones entre el miedo y la comunicación. En principio, puede encontrarse una profunda relación entre los estudios que vinculan el miedo como un recurso político - siguiendo un postulado casi hobbesiano- y su uso en los medios de comunicación masiva. Así, autores como Carman (2008), Salazar (2011) y Mantilla (2008) coinciden con González (2007), quien afirma que el miedo es utilizado por los poderes hegemónicos para dominar al conjunto de población, y que en ello, los medios masivos de comunicación juegan un papel vital, pues se convierten en el vehículo para difundir determinados temores. La posición de estos autores es consecuente con la planteada por Noam Chomsky y Edward Herman en los Guardianes de la libertad: propaganda, desinformación y consenso en los medios de comunicación de 
masas (1990), quienes en su obra argumentan que los medios masivos de comunicación están al servicio de las élites políticas y/o económicas y, por tanto, son vehículos que difunden información que favorece los intereses de dichas élites. Desde esta perspectiva, aparecen actores que de manera soterrada han usado los medios de comunicación masiva como un medio para difundir temores hacia hechos, asuntos, organizaciones, personas o comportamientos específicos. El miedo resulta ser un asunto estructural en el mundo actual; no surge al azar, sino bajo una suerte de complot que pretende que el miedo exista, crezca y se reproduzca con el objetivo de dominar a la población a través de este, para condicionar el actuar de las personas en materia de seguridad, así como impulsar el consumo de cierto tipo de productos.

En oposición a lo anterior, Enrique Gil Calvo (2004) plantea un supuesto enteramente diferente: el miedo efectivamente es un asunto estructural del mundo contemporáneo, pero este no es impulsado por intereses ocultos, sino que hace parte del sistema mismo. Consecuente con lo enunciado por Ulrich Bech en la Sociedad del riesgo, este aumento en las interacciones entre los individuos, aumenta las posibilidades de que se produzcan crisis y catástrofes. Esto debido a que como plantea el "axioma maltusiano, de que si las interacciones crecen linealmente, la probabilidad de ocurrencia de accidentes crece geométricamente" (Gil, 2004,35). Así, los riesgos reales aumentan de manera casi invisible sin que la ciencia o las potenciales víctimas descubran y puedan así evitarlos.

Sin embargo, es necesario destacar que los argumentos de Gil Calvo no se reducen a lo expresado en el párrafo anterior. Su argumento se extiende hasta lo que él denomina, la " epidemiología del alarmismo" y que, en esencia, se fundamenta en el aumento del clima de incertidumbre y ambivalencia social, producto del incremento de las interacciones comunicativas en el mundo contemporáneo. Es decir, debido a que asistimos a un mundo globalizado conocido como la era de la información o la era de los medios de comunicación, cualquier evento que suponga un peligro o amenaza es rápidamente transmitido en los medios de comunicación masiva y reproducido en radio, televisión, prensa, cine, Internet y así, en cada dispositivo electrónico. De esta manera, las imágenes de atentados, catástrofes o crisis se dispersan rápidamente por todo el planeta y son reproducidas incesantemente hasta que aparezca otra amenaza.

Hoy día, una de las funciones principales de la opinión pública es precisamente crear alarma social, dado que se ha convertido en su principal función institucional Por tal razón, la realidad nos parece temible porque la opinión pública así lo ha determinado, independiente de que existan riesgos reales que justifiquen tal temor. En este punto, Gil Calvo expresa claramente que hay individuos o instituciones que efectivamente se benefician del miedo social, como lo pueden ser algunos medios de comunicación interesados en crear alarma para aumentar su rating o algunos gobiernos empecinados en crear temor para aumentar el nivel de control social que ejercen sobre sus ciudadanos. No obstante, abundan los casos donde no se vislumbran intereses claros en crear alarma social y esta aparece inequívocamente, puesto que lo único que siempre se precisa para crearla es la existencia de una red de interacción. (Gil, 2004, 40 y ss). 
Entonces, resulta aquí importante cuestionarse cómo se hace visible el miedo en los medios de comunicación, cómo puede rastrearse visualmente. Surge así la idea de que la visualidad es un dispositivo técnico y discursivo derivado de su presencia en un medio de comunicación. Desde esta perspectiva, se entiende también el que el miedo no solo se hace visible a través de una imagen, sino que también toca el ámbito discursivo. Así, la prensa escrita hace visible al miedo por medio de sus titulares o en la narrativa sobre la cual está construida. Sin embargo, cuando se confronta esto con el discurso publicitario en la ciudad, se advierte que efectivamente el miedo no aparece de manera literal; todo lo contrario, este cobra sentido en su ausencia, pues dicho tipo de discurso persuasivo trabaja sobre la metáfora y la solución a este. Aquí se hace realidad uno de los planteamientos de Delumeau (1989), el cual plantea que el miedo ha sido constantemente tratado como tabú, algunas veces, mostrándose sin tapujos y en otras ocultándose, a pesar de que su existencia siempre se mantenga.

Si esta información es comparada con la posición sostenida por Melissa Salazar (2011), quien plantea que el sistema económico capitalista y las instituciones que soportan este modelo dominante han desarrollado unos mecanismos que separan claramente a aquellos grupos poblacionales que se han insertado de manera efectiva en el sistema imperante, de aquellos individuos que no han logrado hacerlo, podemos advertir que esencialmente los medios de comunicación masiva contribuyen a esta segregación. Quiere decir esto que quienes no se han logrado insertar en el sistema capitalista no aparecen en los medios masivos de comunicación y no tienen ninguna injerencia en él.

Desde esta perspectiva es necesario reconocer que, aunque si bien en el mundo contemporáneo hay inagotables fuentes de amenaza, y por tanto, inagotables fuentes de miedo, no todas son dignas de aparecer en los medios de comunicación. Es decir, si entendemos-siguiendo a Chomsky-que los medios de comunicación masiva son propiedad de las élites políticas y económicas y que la información allí producida es desarrollada por funcionarios especializados pertenecientes a diversas clases económicas de la sociedad -a diferencia de los desclasados- o, por lo menos, por funcionarios insertos en las dinámicas económicas del capitalismo, entenderemos que la información que allí aparece y específicamente, los miedos que se hacen visibles son aquellos que afectan a las élites y a la población que está inserta en el sistema económico capitalista.

Asimismo, quienes hoy día tienen acceso a dispositivos electrónicos y en esencia hacen parte de una red de interacción - digamos que- global son aquellos que se han insertado de manera alguna en el sistema económico capitalista. Así, los miedos que circulan en estas redes de interacción y que han sido visualizados en los medios de comunicación masiva son aquellos que también afectan a sus diversos enlaces dentro de la red. Quiere decir esto que aquellos individuos que no pudieron insertarse en el sistema capitalista, no solo son segregados de diversas formas, sino que paulatinamente son invisibilizados por los medios de comunicación masiva, y con ellos, también son invisibilizados sus miedos.

Desde la perspectiva de Carman (2011), esta situación permite que surja una dinámica perversa, pues aquellos individuos excluidos del sistema no son vistos como víctimas, 
sino que paradójicamente se convierten en victimarios, teniendo en cuenta que son presentados homogéneamente como habitantes de las zonas más peligrosas de las ciudades y, por tanto, son vistos como delincuentes o sospechosos de serlo. En consecuencia, los indigentes, desclasados o desempleados son presentados como una carga para el sistema, se les niegan los beneficios del Estado y son presentados como una fuente de peligro para la estabilidad social.

Por tal razón, se entiende la necesidad de las clases medias y altas de crear barreras físicas entre las zonas de la ciudad que ellos habitan y las zonas deprimidas que son catalogadas como peligrosas. Las urbanizaciones cerradas, protegidas por altos muros y vigilantes armados son una herramienta frecuente que separa a sus residentes del mundo exterior. Sin embargo, en los puntos de la ciudad donde la construcción de muros se hace imposible, como en el caso de los espacios públicos, el miedo será un sentimiento constante mientras esta dinámica se mantenga (Carman, 2011).

\section{Visualidades del miedo en la Medellín contemporánea}

El conflicto armado que ha vivido Medellín desde la década de los años ochenta del siglo XX ha sido sobre explorado debido a la abundante literatura que sobre el tema puede encontrarse hoy día. Sin embargo, desde la perspectiva de Elsa Blair, Marisol Grisales y Ana María Muñoz (2009), la gran cantidad de investigaciones realizadas no terminan de explicar acertadamente el origen del conflicto y sus características; esto se debe a que se han basado en el paradigma del conflicto armado, entendiendo este como el enfrentamiento entre el Estado y diversas organizaciones que luchan contra él o -aparentemente-apoyan su accionar, como lo serían los grupos subversivos y las autodefensas, respectivamente. El error de este enfoque -a juicio de las investigadoras- se basa en que Medellín no vive un conflicto armado producto de esta dinámica, sino que experimenta múltiples conflictividades urbanas, donde la dinámica anteriormente mencionada solo es una pequeña parte de esta situación (Blair, Grisales, Muñoz, 2009).

Así, los fenómenos de violencia en diversos barrios de la ciudad se iniciaron con el poblamiento mismo de esas zonas por comunidades que, en ausencia del Estado, se organizaron en grupos de autoprotección compuestos por vecinos, amigos y familiares que solo respondían a los constantes robos y violaciones que sucedían en su entorno. De esta manera, cuando diversas expresiones del conflicto armado en Colombia y posteriormente la incipiente dinámica del narcotráfico ingresaron a la ciudad, lo hicieron siguiendo las dinámicas barriales preexistentes a su llegada, lo que indica que el conflicto armado en la ciudad de Medellín no esté determinado por estrategias políticas de carácter nacional establecidas ni por el Estado, ni por diferentes organizaciones armadas. Todo lo contrario, las dinámicas locales, e inclusive barriales y sus protagonistas, determinan que la violencia desencadenada en la ciudad no sea únicamente de carácter político, sino que muchas veces está impulsada por motivos subjetivos como rencores, venganzas, intereses personales, económicos, etc., los cuales hacen del conflicto en Medellín, un asunto realmente ambiguo. Sin embargo, esta compleja situación desde sus inicios impulsó 
dinámicas de territorialidad, debido al interés de algunos grupos por dominar los barrios y sus habitantes y posteriormente las diferentes fuentes de ingresos económicos, para financiar sus actividades. La dinámica de territorialidad de estos grupos que lentamente fueron catalogándose bajo el título de "combos" o "bandas criminales", permanece hasta hoy día (Blair,Grisales, Muñoz, 2009) y son fuente constante de noticias, especialmente en lo concerniente a las "fronteras invisibles" las cuales determinan los límites de estos territorios controlados por dichas bandas.

Desde esta perspectiva no resulta sorprendente que el miedo hacia estos actores y las zonas de la ciudad que dominan sea uno de los que más se hace visible en los medios de comunicación masiva. Es decir, efectivamente en la prensa escrita de la ciudad, aparecen varias amenazas que se convierten en fuentes del miedo. Sin embargo, la que aparece con más fuerza y de una manera reiterada es el miedo a la violencia desatada en algunos sectores de la ciudad. El cierre de instituciones públicas, los paros armados, las quejas de los conductores de buses que son extorsionados constantemente, los enfrentamientos entre diferentes grupos armados y los esfuerzos de las autoridades por desarticular estas bandas son noticias que se destacan tanto en titulares de primera página, como en la extensión en el desarrollo de las noticias en el periódico. De igual forma, se destaca a diversas bandas criminales como actores de primer orden en estos actos violentos; así, por ejemplo, cobran especial importancia las noticias donde diversos combos acuerdan o dan por terminadas diferentes treguas a sus continuos enfrentamientos armados.

Si bien las bandas criminales no son las únicas fuentes de violencia en Medellín, sí juegan un papel destacado en las noticias de la ciudad, situación por la cual se convierten en un referente periodístico hasta tal punto en que comúnmente, aparecen como las culpables de numerosos hechos violentos. Y en caso contrario, se destaca claramente la no participación de estas bandas en determinados actos delincuenciales de la ciudad, situación que confirma cómo estas se convirtieron en un referente periodístico en la ciudad.

Si retomamos la idea en que los grupos marginados no tienen acceso a los medios de información o por lo menos, sus puntos de vista no alimentan los contenidos de estos medios, puede verse cómo en los casos en que determinadas comunidades marginadas se enfrentan por diversos motivos a la fuerza pública son presentadas -las comunidades-como las culpables del enfrentamiento. Así -por lo menos, en el período objeto del estudio-, no se muestra a las autoridades y sus posibles abusos de la fuerza como un hecho digno de ser temido, sino, por el contrario, a lo que debemos temer es a la respuesta de estas comunidades, pues abiertamente se oponen al ejercicio de la autoridad.

Surgen así, tanto en los medios de comunicación como en el imaginario social, unas zonas de la ciudad que son mucho más peligrosas que otras y por tanto, son dignas de ser temidas. Los barrios periféricos que se ubican hacia el noroccidente y nororiente de la ciudad son presentados como los sectores donde más amenazas a la seguridad individual y colectiva se presentan. Por tal razón, también se registra un importante número de noticias donde si bien no se muestra directamente a estas zonas como áreas de la 
ciudad sumidas en la violencia, sí presentan a las zonas aledañas como peligrosas, lo que permite inferir que el riesgo radica en la cercana ubicación de algunos espacios públicos con estos barrios deprimidos. De este modo, abundan las noticias en donde se informa acerca de muertes violentas, atracos y robos en las cercanías a barrios periféricos y el temor que producen estas acciones delictivas cercanas por ejemplo a barrios como Castilla, La Iguaná y Manrique, catalogados tradicionalmente como peligrosos sectores de la ciudad.

Otra importante fuente del miedo, detectada en la prensa escrita de la ciudad y luego corroborada en la opinión pública, es aquel producido por la posibilidad de perder el empleo o ser víctima de crisis económicas que disminuyan considerablemente el poder adquisitivo. Así, es relativamente fácil encontrar noticias que insistentemente pongan en evidencia las incertidumbres causadas por los vaivenes de la economía y los bajos crecimientos económicos. Los titulares de despidos y el desempleo, aparecen de manera reiterada para recordarles a los lectores que no solo la vida es frágil, sino también los bienes adquiridos y las comodidades acumuladas y disfrutadas hasta el momento son susceptibles de perderse por situaciones que no son controlables por los individuos.

Si comparamos estas noticias con la posición sostenida por Carman (2011) y Salazar (2008), es posible afirmar que la pérdida de empleo o el empeoramiento de la situación económica traen como consecuencia el detrimento de la capacidad adquisitiva de los individuos y, por tanto, la posibilidad de mantenerse insertos dentro del sistema capitalista. Así, cuando un individuo es incapaz a través de su trabajo o sus inversiones, de mantenerse dentro del sistema, es catalogado paulatinamente como una carga para este, siendo obligado al mismo tiempo a buscar su sustento económico en la informalidad que generalmente se desarrolla en el espacio público y, además, a habitar las zonas de la ciudad que han sido destinadas para los desclasados y desempleados, es decir, las zonas periféricas que se consideran más peligrosas. Entonces, ser víctima de una crisis económica duplica el sentimiento de vulnerabilidad y, por tanto, la propensión a sentir miedo, pues se corre un mayor peligro de ser víctima de la violencia y de ser catalogado posteriormente como una amenaza.

\section{Los espacios comerciales como lugar del consumo y antídoto del miedo}

Al igual que la separación entre política y religión, la división entre las esferas pública y privada es una de las características más importantes de la Modernidad. Bajo esta disyuntiva se ha entendido, por una parte, que las creencias, las opciones de vida y las acciones sociales son un asunto netamente privado y por tanto, de responsabilidad exclusiva de los individuos. Por otra parte, la esfera pública se convirtió en un campo donde convergen, de manera especializada, la política, la economía y los asuntos intelectuales "limpios" de las tradiciones no modernas (Patiño, 2006).

Diversos autores califican a lo público como un concepto que supera al Estado, a lo publicable o a lo propio del espacio público, definiendo a la esfera de lo público como aquella propia de lo común, lo perteneciente a todos, lo de interés general, lo visible, lo manifiesto y lo accesible (Galvis, 2005). Sin embargo, es necesario destacar que en el 
contexto de la Modernidad, fue el Estado moderno quien se atribuyó el derecho y deber de regular las prácticas e interacciones sociales, las relaciones de poder, los intercambios económicos y los proyectos sociales en el contexto de la esfera pública. Así, aunque este contexto sea más amplio, ha sido interpretado por el Estado como el escenario ideal donde este puede ejercer plenamente su poder. Desde esta perspectiva, no resulta extraño que tradicionalmente sobre el espacio público se generen profundas fricciones entre el poder del Estado y los micropoderes de organizaciones e individuos que se oponen a este y al mismo tiempo velan por sus propios intereses. En el mundo contemporáneo, el debilitamiento paulatino de los Estados Modernos o Estados Nacionales, ha influido directamente en la pérdida que alguna vez ostentó el Estado para gestionar estos espacios públicos que alguna vez consideró de su entera autonomía.

Los miedos hasta aquí enumerados afectan la esfera privada de la población; sin embargo, tienen un origen en el contexto público. Son producidos por factores externos que están por fuera del dominio y control de los individuos corrientes. Los riesgos producto de la inseguridad, los factores económicos, las catástrofes, sean naturales o producto de la actividad humana, las infecciones, son siempre percibidas como un factor de origen externo y por tanto, donde el Estado tiene el deber de intervenir. Dicho esto, la mejor solución para combatirlo es encerrarnos en nosotros mismos, o por lo menos, limitar o controlar nuestro contacto con el mundo exterior y con lo público, espacio donde habita el otro, el desconocido. Así las cosas, los condominios cerrados, las puertas blindadas, las alarmas, el monitoreo de cámaras, la vigilancia privada y los centros comerciales se muestran como una solución idónea para aislarnos de los otros, en un espacio seguro y controlado por personal que garantiza nuestra seguridad con estándares mucho más altos de lo que puede ofrecernos el Estado.

Sin embargo, si seguimos la perspectiva de González (2007), existe otro miedo que los medios periodísticos no hacen visible en la ciudad de Medellín, pero que sí existe en la realidad cotidiana de las sociedades posmodernas: el miedo a la soledad, a la incapacidad de establecer relaciones amorosas o fraternas con otras personas. Por tal razón, los artilugios anteriormente descritos no nos aíslan del todo, solo lo necesario. Nos permiten llevar una vida normal, tranquila y segura, y al mismo tiempo, nos invitan a realizar en compañía las actividades que más nos gustan. Nos aíslan del miedo y de los desconocidos, pero nos permiten relacionarnos con personas de la misma clase social.

No resulta extraño entonces que se nos venda la idea de que los centros comerciales no solo son espacios seguros para ir de compras, sino que también son espacios idóneos para el encuentro, para divertirse, socializar, hacer deporte, escuchar un concierto, apreciar una muestra de teatro y hasta ir a misa. Incluso se nos ha presentado como el nuevo espacio público, en la medida en que pretenden mostrarse como parques o plazas de la ciudad, con arquitectura monumental que los convierte en referentes urbanísticos.

En este intento, la publicidad ha jugado un exitoso y destacado papel, exhibiendo solo lo digno de ser mostrado. Es decir, en el discurso publicitario es importante lo que 
se enuncia y también lo que no, puesto que las ausencias tienen una importancia destacada, situación por la cual, en la publicidad, el miedo no se ve. No aparece de manera explícita. Sin embargo, sí es un movilizador oculto de la comunicación, y las soluciones a este aparecen de manera reiterada en los anuncios publicitarios. Por ejemplo, uno de los miedos que acechan a las personas que tienen inversiones económicas importantes, es la pérdida de sus capitales a manos de empresas o terceros que de manera equivocada o irresponsable manejen sus dineros. Así, en los anuncios publicitarios de las empresas que buscan cautivar a este público, nunca se mostrará ese miedo latente, pero sí aparecerá la solución a ese temor a través de la solidez y la seriedad.

En tal sentido, la publicidad de los centros comerciales no solo se enfoca en la posibilidad de que estos establecimientos ofrezcan gran variedad de marcas y productos, cosa de por sí obvia, sino que se centran en mostrar sus espacios como sitios especialmente diseñados para compartir en familia o propiciar el encuentro entre parejas y amigos. Precisamente, por citar solo tres ejemplos, el Parque Comercial el Tesoro, se muestra efectivamente como un parque, (y se privilegia en el discurso), su ambiente natural, sus juegos infantiles y sus espacios para disfrutar en familia. En oposición a lo anterior, el Mall Del Este, ubicado en la calle contigua al Tesoro, se enfoca a un público objetivo soltero con gran capacidad adquisitiva. Por tal razón, este espacio comercial se presenta como un sitio propicio para el encuentro, para trabajar o pasar la tarde en compañía. Los productos ofrecidos por las marcas que están en el interior del centro comercial pasan a un segundo plano, pues lo que realmente importa es presentarse como solución a esos temores. Finalmente, Punto Clave que, con el objetivo de construir un beneficio diferenciador, anuncia haberse convertido en un centro integral de servicios, pero que en términos reales también ofrece los productos y las marcas de cualquier centro comercial, ofrece en su publicidad, la posibilidad de reunir en un solo espacio todos los locales de servicios que generalmente estaban ubicados en el centro de la ciudad. Así, invita a su público a dejar de someterse a las incomodidades del centro para preferir la tranquilidad y seguridad del centro comercial.

Las fotografías de bellos niños sonrientes, parejas felices o grupos de amigos que departen juntos son una constante en la publicidad de estos negocios, generalmente acompañadas por imágenes de fachada de los centros comerciales, las cuales no solo sirven para ayudar al público a reconocer el espacio del cual se habla, sino que también indican indica que esta arquitectura monumental es cerrada y no permite fácilmente la entrada de "personas indeseadas". El miedo al aburrimiento, la soledad, la calle y al desconocido pretenden haber sido superados.

\section{Conclusiones}

El miedo y la victimización no son lo mismo; sin embargo, los miedos visualizados en la ciudad de Medellín sí están íntimamente ligados a la posibilidad de convertirse en una víctima. Dichos miedos pueden clasificarse en cuatro categorías de acuerdo con la importancia en que aparecen en los medios de comunicación, específicamente en la publicación objeto del estudio, según su ubicación en los ejemplares, la extensión de la 
noticia y la utilización de fotografías que apoyan el texto presentado. En este sentido, los miedos que más se presentaron son: a la violencia física, expresada a través de asesinatos, robos y extorsiones principalmente; en segundo lugar, aparece el miedo a los infortunios económicos, ya sea a través de la pérdida del empleo o ser víctima de una crisis económica; en tercer lugar, se presentó el miedo a los cambios climáticos que la ciudad ha venido experimentando de forma acelerada en los últimos años y que se materializaron principalmente en avalanchas, derrumbes y, en menor medida, en inundaciones. Finalmente, una cuarta categoría del miedo sería el que se presenta ante la posibilidad de ser víctima de una enfermedad que esté por fuera del cubrimiento del Plan Obligatorio de Salud, POS, las cuales son conocidas como enfermedades ruinosas.

Así, el miedo a la inseguridad es el que más se visualiza, puesto que aparece constantemente en los medios de comunicación y hace parte del imaginario de ciudad. De igual forma, las noticias que hacen mención a estos temas contienen información acerca del lugar donde se presentan los actos delictivos, por lo cual algunos sectores de la ciudad son presentados como más peligrosos que otros. El centro de la ciudad y los barrios periféricos de los sectores nororiental y noroccidental son presentados como lugares destacadamente peligrosos y, por tanto, dignos de ser temidos. En tal razón, puede afirmarse que los hechos generadores de miedo pueden ubicarse geográficamente hasta afirmar que es posible crear una geografía del miedo, inicialmente en los espacios públicos y especialmente en los sectores anteriormente mencionados.

Ante esta realidad donde el espacio público está salpicado de riesgos y factores generadores de temor, aparecen múltiples antídotos entre los cuales se destaca el centro comercial, presentado como un oasis al caos y al peligro de la ciudad, además, como el sitio idóneo para consumir y ser feliz. Se muestra así a este tipo de edificaciones como un espacio que recoge las mayores cualidades de los espacios abiertos, los cuales posibilitan la vida en familia, las nuevas experiencias, las relaciones interpersonales y el encuentro de aquellos que están insertos en el sistema y que hacen parte de la misma clase social. Todo esto, de una manera aséptica, alejada del caos del verdadero espacio público y de aquellos que están fuera del sistema capitalista y que a final de cuentas son considerados los peligrosos.

\section{Bibliografía}

Álvarez, M. Arango, C. (2011). Nuevas recepciones, viejos consumos: las recientes ofertas de contenidos como agentes de transformación de lo imaginario. Anagramas. Rumbos y sentidos de la comunicación. Volumen 10 núm. 19. pp. 17-34

Atkin, D. (2004) El culto a las marcas. Cuando los clientes se convierten en creyentes. Barcelona: Ediciones Robinbook.

Balandier, G. (1994). El poder en escenas: de la representación del poder al poder de la representación. Barcelona: Paidós.

Blair Trujillo, E., Grisales Hernández, M., Muñoz Guzmán, A. (2009, enero-junio). Conflictividades urbanas versus"guerra"urbana: otra "clave" para leer el conflicto en Medellín. Universitas Humanística, núm. 67. pp. 29-54 
Carman, M. (2008, septiembre-diciembre). "Usinas del miedo“ y esquizopolíticas en Buenos Aires. AIBR. Revista Antropológica Iberoamericana. Volumen 3 N. 3. pp. 398-418.

Chomsky N., y Herman E., (1990) Los guardianes de la libertad: propaganda, desinformacion y consenso en los medios de comunicación de masas. España: Crítica Grijalbo.

Delumeau, J. (1989). El miedo en Occidente: siglos XVI-XVIII. Madrid: Taurus.

Foucault, M. (1980). Vigilar y castigar: nacimiento de la prisión. México: Siglo XXI

Galvis, C. (2005). La comunicación pública como hologramía de la crisis.F@Ro: Revista Teórica del Departamento de Ciencias de la Comunicación y de la Información. Volumen 1 fasc. 1 pp. 841-856

González, E. (2007). Biografía del miedo. Barcelona. Random House Mondadori.

Lyotard, J. (1991). La condición posmoderna. Madrid: Cátedra.

Mantilla Valbuena, S. (2008, enero-junio). Más allá del discurso hegemónico: narcotráfico, terrorismo y narcoterrorismo en la era del miedo y la inseguridad global. Papel Político, Volumen $13 \mathrm{~N} .{ }^{\circ} 1$ pp. 165-206.

Patiño, C. (2006, noviembre-diciembre). Religión, política e identidad colectiva: ¿un problema nuevo en el siglo XXI? Árbor Ciencia, Pensamiento y Cultura, Volumen 32 N. ${ }^{\circ}$ 722. pp. 763-773

Salazar Echeagaray, M. (2011, noviembre-diciembre). La dimensión mediática de la estrategia de miedo y securitización en América Latina. El cotidiano, núm. 170, pp. 101-110.

Se dispara la inversión en centros comerciales. 11 de agosto de 2013. En:

http://www.elcolombiano.com/BancoConocimiento/S/se_dispara_la_inversion_en_centros_ comerciales/se_dispara_la_inversion_en_centros_comerciales.asp Arias Ferney. 